九州大学学術情報リポジトリ

Kyushu University Institutional Repository

\title{
Physical and Chemical Properties of Water Treatment Residue and the Characteristics of Red Pepper Growth by Using it
}

Park, Seok-Gon

Institute of Tropical Agriculture, Graduate School of Social and Cultural Studies, Kyushu University

Yahata, Hisashi

Emeritus professor of Kyushu Univerisy

Kurosawa, Kiyoshi

Institute of Tropical Agriculture, Graduate School of Social and Cultural Studies, Kyushu University

Shin, Hyun-Tak

Gyeongsangnam-do Forest Environment Research Institute

https://doi.org/10.5109/17812

出版情報: 九州大学大学院農学研究院紀要. 55 (1)，pp.117-122，2010-02-26. Faculty of Agriculture, Kyushu University

バージョン :

権利関係 : 


\title{
Physical and Chemical Properties of Water Treatment Residue and the Characteristics of Red Pepper Growth by Using it
}

\author{
Seok-Gon PARK ${ }^{1 *}$, Hisashi YAHATA ${ }^{2}$, Kiyoshi KUROSAWA ${ }^{1}$ \\ and Hyun-Tak SHIN ${ }^{3}$
}

\author{
Institute of Tropical Agriculture, Kyushu University, Hakozaki, 6-10-1, \\ Fukuoka 812-8581, Japan \\ (Received October 30, 2009 and accepted November 19, 2009)
}

\begin{abstract}
Physical and chemical properties of the water treatment residue (WTR) and the $\mathrm{WTR}_{\mathrm{CP}}$, which contained compost (CP), were measured, and the effect of the properties on growth of the red pepper (Capsicum annuum 'Takanotsume') was studied to reuse the WTR as an alternative material for decomposed granite soil (DGS). The physical properties of relative gas diffusivity (D/ $\left.\mathrm{D}_{0}\right)$, saturated hydraulic conductivity $\left(\mathrm{K}_{\mathrm{s}}\right)$, water retention curve, porosity and plant-available water, and the chemical properties of total-N and cation-exchange capacity (CEC), etc. were compared between the WTR and DGS, and between the $\mathrm{WTR}_{\mathrm{CP}}$ and $\mathrm{DGS}_{\mathrm{CP}}$, respectively. D/D, $\mathrm{K}_{\mathrm{s}}$, total-N and CEC were higher in $\mathrm{WTR}_{\mathrm{CP}}$ than in DGS $\mathrm{CP}_{\mathrm{CP}}$ The growth of the red pepper was better in $\mathrm{WTR}_{\mathrm{CP}}$ than in $\mathrm{DGS}_{\mathrm{CP}}$ because the physical and chemical properties of the $\mathrm{WTR}_{\mathrm{CP}}$ were considered to be beneficial to the growth of the red pepper. The WTR $\mathrm{CP}_{\mathrm{C}}$ was suitable as an alternative material of $\mathrm{DGS}_{\mathrm{CP}}$.
\end{abstract}

\section{INTRODUCTION}

Water treatment residue (WTR) is the by-product from the production of the potable water (Titshall and Hughes, 2005). Most of WTR are discarded at landfill sites or waste disposal stations everywhere in the world (Heil and Barbarick, 1989; Moodley et al., 2004; Titshall and Hughes, 2005; Babatunde and Zhao, 2007).

Technology that can reuse a large amount of WTR is required. Following examples to reuse the WTR as a substitute soil materials were reported; clay substitute material of cement and brick manufacture (Pan et al., 2004; Ramadan et al., 2008), subbase material of geotechnical works (Furukawa et al., 2006). Currently, applications of the WTR as a soil amendment is gaining increasing attention as an alternative landfill option for its recycling (Heil and Barbarick, 1989; Moodley et al., 2004; Moodley and Hughes, 2006).

However, typically high application rate of the WTRs $(>10 \%)$ cause the deficiency of plant-available phosphorus (P) for plants (e.g., Elliott and Singer, 1988; Dayton and Basta, 2001). Ahmed et al. (1997) investigated the water retention characteristics of the WTR and concluded that WTR was unsuitable for use it as a growth medium due to its low plant available water content. Little information is available to use the WTRs as an alternative soil material (Dayton and Basta, 2001).

On the other hand, Roppongi (1993) suggested that the possibility to reuse the WTR to which organic matter (OM) was added as an alternative soil material. He

Institute of Tropical Agriculture, Graduate School of Social and Cultural Studies, Kyushu University, 819-0395, Fukuoka, Japan

${ }^{2}$ Emeritus Professor of Kyushu University, 812-8581, Fukuoka, Japan

Gyeongsangnam-do Forest Environment Research Institute, Jinju-si, 660-871, Korea

* Corresponding author (E-mail: park@agr.kyushu-u.ac.jp) reported that the vegetables growth in the WTR to which hull and sawdust-cattle manure were mixed was similar to that in nursery soil (control). Elliot and Dempsey (1990) showed that the WTR generally had little fertilizer value. The addition of fertilizer and/or OM, such as compost and biosolids, can help to improve nutritional value of the WTR. With regard to potential fixation of plant-available P, Hyde and Morris (2004) noted that amendment of WTR with P before application to agricultural soil may eliminate the problem of $\mathrm{P}$ deficiencies for plant growth. Park et al. (2009) reported that the available water capacity of the WTR was increased by the adjustment of particle size distribution and the pore structure of the WTR. Moreover, the aeration and water retention ability of the WTR were superior to the decomposed granite soil (DGS).

Red peppers grow well on loamy soils rich in $\mathrm{OM}$; Since inadequate field drainage results in a low yield of the red pepper, the plant should be grown in welldrained plots; The optimum $\mathrm{pH}$ ranges for the red pepper were from 6.0 to 7.0 , and the plant is fairly tolerant to soil acidity. A large number of the red pepper cultivars is suited to an atmospheric temperature ranging from 21 to $25^{\circ} \mathrm{C}$, while very high temperatures (above $32^{\circ} \mathrm{C}$ ), lead to parthenocarpy; Irrigation should be moderately adjusted because the red pepper roots are highly susceptible to excessive soil moisture (AICAF, 1993).

The our purposes of this study are therefore, 1) to compare physical and chemical properties between the WTR and DGS, and between the $\mathrm{WTR}_{\mathrm{CP}}$ and DGS $\mathrm{DP}_{\mathrm{CP}}$, which contained OM, and 2) to clarify the effect of the properties above mentioned on a growth of red pepper, which is used as a representative crop plant, in order to examine the possibility of reuse of $\mathrm{WTR}_{\mathrm{CP}}$ for an alternative material of DGS $_{\mathrm{CP}}$. 


\section{MATERIALS AND METHODS}

\section{Materials and its treatment}

The WTR was collected from the Tatara Water Purification Plant in Fukuoka City, Japan for the experimental use. Nearly $0.02 \mathrm{~m}^{3}$ in volume of the WTR was collected from the plant in 2007. The WTR was produced from aggregates by a flocculation process with polyaluminium chloride and dehydration by filter press in the filtration process. The original WTR materials were angular blocks of 12-35 mm long and wide and 4 $\mathrm{mm}$ thick having an average water content of 121\% (w $\mathrm{W}^{-1}$ ). Those WTR were ground and sieved into particles less than $3 \mathrm{~mm}$ in diameter. DGS of around $0.02 \mathrm{~m}^{3}$ was collected from Mt. Tachibana in Fukuoka Prefecture in 2007. The DGS was sieved to particles of less than $3 \mathrm{~mm}$ in diameter.

Particle density of the collected WTR and DGS was measured by the pycnometer method and was $2.35 \mathrm{Mg}$ $\mathrm{m}^{-3}$ and $2.69 \mathrm{Mg} \mathrm{m}^{-3}$, respectively. The particle size distribution of the WTR and DGS was determined by dry sieving and the hydrometer method (Gee and Or, 2002). The WTR consisted mostly of sand (78.0\% in content), and the content of clay was very low (2.4\%). While the DGS consisted of gravel (47.2\%) and sand (45.7\%). The WTR and DGS belonged to loamy sand, and sandy loam, respectively by US Department of Agriculture scheme.

Compost (CP) was added to the WTR and DGS for making growth medium. The $\mathrm{CP}$ was matured cattle manure and wood waste from commercial products (Orizin, dozyoubiseibutsu Inst. Inc., Japan). This CP was also sieved to less than $3 \mathrm{~mm}$. The particle size of nearly half in amount of the $\mathrm{CP}$ was $>1 \mathrm{~mm}$ in diameter. The electrical conductivity, total-N and cation-exchange capacity of the CP employed in the study were $20.0 \mathrm{dS}$

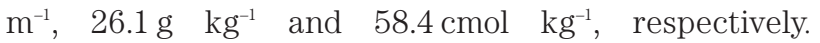
Exchangeable bases $\left(\mathrm{K}^{+}, \mathrm{Ca}^{2+}, \mathrm{Mg}^{2+}\right)$ and plant-available $\mathrm{P}$ of the $\mathrm{CP}$ were $798.0,80.6$ and $64.3 \mathrm{cmol} \mathrm{\textrm {kg } ^ { - 1 }}$, and $460.2 \mathrm{mg} \mathrm{kg}^{-1}$, respectively.

For WTR and DGS, the CP was added at $10 \%$ of the total volume of the dried originals of WTR and DGS. The original WTR and DGS are denoted as WTR and DGS, and the CP added WTR and DGS are denoted as $\mathrm{WTR}_{\mathrm{CP}}$ and $\mathrm{DGS}_{\mathrm{CP}}$ hereafter, respectively.

\section{Physical and chemical properties}

To measure the physical properties of the $\mathrm{WTR}_{\mathrm{CP}}$ and DGS $_{\mathrm{CP}}$, the air-dried samples of these were packed uniformly by hand into stainless steel cylinder (51 mm high and $50 \mathrm{~mm}$ i.d.) with three replications. The samples were saturated by the upward infiltration method overnight, and saturated hydraulic conductivities $\left(\mathrm{K}_{\mathrm{s}}\right)$ of samples were measured by the falling head method (Reynolds et al., 2002). Then the water retention curves of the samples were determined at $-1,-4,-6,-13,-40$, $-100,-600$ and $-1,500 \mathrm{kPa}$ matric potentials in the water desorption process (Flint and Flint, 2002). Here, water contents were measured at high matric potentials of $-6 \mathrm{kPa}$ by the hanging-water column method (Dane and Hopmans, 2002a), and at $-40 \mathrm{kPa}$ by the pressure plate method (Dane and Hopmans, 2002b). Moreover, water content at the low matric potentials of -600 and $-1,500 \mathrm{kPa}$ was determined by the centrifuge method (Reatto et al., 2008).

Gas diffusivity (D) was measured at -6 and $-100 \mathrm{kPa}$ matric potentials. Relative gas diffusivity $\left(\mathrm{D} / \mathrm{D}_{0}\right)$ was determined by the methods shown by Osozawa (1987) and Rolston and Moldrup (2002). Then, the bulk density $(\mathrm{Bd})$ and gravimetric water content were obtained by weighing the oven-dried samples for $24 \mathrm{hrs}$ at $105^{\circ} \mathrm{C}$. Total porosity was calculated from the bulk density and particle density (Flint and Flint, 2002). The total porosity is the sum of capillary and macro porosities. The capillary porosity (capillary water) was defined as the amount of water retained at $-4 \mathrm{kPa}$ (Bigelow et al., 2004), while the macro porosity was determined by subtracting the amount of water at $-4 \mathrm{kPa}$ from total porosity. The amount of plant-available water (PAW) for $\mathrm{WTR}_{\mathrm{CP}}$ and $\mathrm{DGS}_{\mathrm{CP}}$ was determined as the water content difference between the matric potentials at -6 and -1,500 Pa (Moodley et al., 2004). These determined data of physical properties of the WTR and DGS were cited from Park et al. (2010).

The samples of WTR, DGS, WTR $\mathrm{CP}_{\mathrm{CP}}$ and $\mathrm{DGS}_{\mathrm{CP}}$ were air-dried and gently ground to pass through a $2 \mathrm{~mm}$ sieve for chemical analysis. The $\mathrm{pH}$ of samples was determined in a 1 (water): 2.5 (sample) calcium chloride $\left(\mathrm{CaCl}_{2}\right)$ solution using a glass electrode. Electrical conductivity (EC) was measured in a 1 (water): 5 (sample) deionized water solution. Cation-exchange capacity (CEC) and exchange bases were determined by the $\mathrm{NH}_{4}{ }^{+}$-acetate method and the $1 \mathrm{M} \mathrm{NH}_{4}{ }^{+}$-acetate extraction method at pH 7 (Sumner and Miller, 1996). Total-C and total-N were determined by using a CN corder (MT-5, CHN corder, Yanaco New Science Inc., Japan) and amount of plant-available $\mathrm{P}$ by using dilute acid method (Kuo, 1996). P-adsorption coefficient was determined by the vanadomolybdate spectrophotometric method (SEAC, 1997).

\section{Greenhouse growth experiment}

Greenhouse growth experiment was conducted using $\mathrm{WTR}_{\mathrm{CP}}$ and $\mathrm{DGS}_{\mathrm{CP}}$. Each $\mathrm{WTR}_{\mathrm{CP}}$ and $\mathrm{DGS}_{\mathrm{CP}}$ was placed in a plastic pot (20 cm tall, $11 \mathrm{~cm}$ i.d.). Red pepper (Capsicum annuum 'Takanotsume') was chosen to compare plant growth between the treatments, because the plant's growth and root swelling were comparatively early, and it was sown at a rate of five seeds per pot. After seedings emerged, all but the one strongest plant were removed. The seedlings were grown in a glass-covered greenhouse controlled at $30{ }^{\circ} \mathrm{C}$ under natural light condition for 14 weeks, from January 20 to April 18. Seedlings were watered as needed.

The pots were arranged in a randomized complete block design with six replications. At the end of experiment, growths of height, root-collar diameter and dry mass of the whole seedlings were measured. For the determination of dry mass, the seedlings were ovendried at $75^{\circ} \mathrm{C}$ for $48 \mathrm{hrs}$. Growth experiment was carried 
out in controlled greenhouses at the Biotron Institute, Kyushu University, Fukuoka, Japan.

\section{Statistical analysis}

Statistical difference of the growths of red pepper between WTR $_{\mathrm{CP}}$ and $\mathrm{DGS}_{\mathrm{CP}}$ was examined by a t-test for the mean difference between them by using the SPSS software (Version 11). To test the differences of the physical properties among WTR, DGS, $\mathrm{WTR}_{\mathrm{CP}}$ and DGS $_{\mathrm{CP}}$, one-way analysis of variance (ANOVA) and Tukey multiple comparison test (Tukey's test) were used.

\section{RESULTS}

\section{Physical and chemical properties of $W_{T R}$ and DGS $_{\mathrm{CP}}$}

Porosity, relative gas diffusivity $\left(\mathrm{D} / \mathrm{D}_{0}\right)$, plant-available water (PAW), bulk density (Bd), saturated hydraulic conductivity $\left(\mathrm{K}_{\mathrm{s}}\right)$ of the samples of WTR, DGS, WTR and $\mathrm{DGS}_{\mathrm{CP}}$ (averaged for the 3 replications, respectively) are shown in Table 1. Total, macro and capillary porosities were significantly higher for $\mathrm{WTR}_{\mathrm{CP}}$ than for $\mathrm{DGS}_{\mathrm{CP}}$, respectively. Because the macro porosity was higher for $\mathrm{WTR}_{\mathrm{CP}}$ than for $\mathrm{DGS}_{\mathrm{CP}}$, the $\mathrm{D} / \mathrm{D}_{0}$ was significantly higher for $\mathrm{WTR}_{\mathrm{CP}}$ than for $\mathrm{DGS}_{\mathrm{CP}}$ at $-6 \mathrm{kPa}$ matric potential. The capillary porosity was higher for $\mathrm{WTR}_{\mathrm{CP}}$ than for $\mathrm{DGS}_{\mathrm{CP}}$, but the PAW was lower for $\mathrm{WTR}_{\mathrm{CP}}$ than for $\mathrm{DGS}_{\mathrm{CP}}$.
The $\mathrm{Bd}$ was significantly lower for $\mathrm{WTR}_{\mathrm{CP}}$ than for DGS $_{\mathrm{CP}}$. Addition of CP to WTR tended to increase the $\mathrm{K}_{\mathrm{s}}$, but the $\mathrm{K}_{\mathrm{s}}$ was not significantly different between the $\mathrm{WTR}_{\mathrm{CP}}$ and WTR. The $\mathrm{K}_{\mathrm{s}}$ was significantly higher for WTR $_{\mathrm{CP}}$ than for DGS $\mathrm{CP}_{\mathrm{C}}$. Addition of CP to WTR increased the macro porosity, but the capillary porosity of the $\mathrm{WTR}_{\mathrm{CP}}$ was decreased. The $\mathrm{D} / \mathrm{D}_{0}$ was increased in $\mathrm{WTR}_{\mathrm{CP}}$ at matric potential of $-6 \mathrm{kPa}$ by the addition of $\mathrm{CP}$, but the $\mathrm{D} / \mathrm{D}_{0}$ of $-100 \mathrm{kPa}, \mathrm{PAW}, \mathrm{K}_{\mathrm{s}}$ and $\mathrm{Bd}$ did not change in $\mathrm{WTR}_{\mathrm{CP}}$.

Chemical properties of the samples are shown in Table 2. In comparison with the neutral DGS, $\mathrm{pH}$ of the WTR was low ( $\mathrm{pH}$ 6.4). EC did not differ largely between the WTR and DGS. Total-C and total-N of the WTR were 130 and 45 times higher than those of the DGS, respectively. P-adsorption coefficient and CEC of the WTR were 14 and 2 times higher than those of DGS, respectively. However, plant-available $\mathrm{P}$ of the WTR was 2.7 times lower than that of DGS. The EC, total-C, total-N, plant-available P, CEC and exchangeable bases were higher for $\mathrm{WTR}_{\mathrm{CP}}$ than those for WTR. However, $\mathrm{pH}$ of the WTR and DGS did not change by the addition of the CP. The EC and total-N of the $\mathrm{WTR}_{\mathrm{CP}}$ were 1.9 and 5.9 times higher than those of $\mathrm{DGS}_{\mathrm{CP}}$, respectively. Moreover, the CEC of the $\mathrm{WTR}_{\mathrm{CP}}$ was 1.9 times higher than that of $\mathrm{DGS}_{\mathrm{CP}}$. However, The $\mathrm{Mg}^{+}$of the $\mathrm{WTR}_{\mathrm{CP}}$ was 7 times lower than that of DGS $_{\mathrm{CP}}$.

Table 1. Porosity, relative gas diffusivity $\left(\mathrm{D} / \mathrm{D}_{0}\right)$, saturated hydraulic conductivity $\left(\mathrm{K}_{\mathrm{s}}\right)$, plant-available water (PAW) and bulk density (Bd) of water treatment residue (WTR), decomposed granite soil (DGS), and $\mathrm{WTR}_{\mathrm{CP}}$ and DGS $\mathrm{CP}_{\mathrm{C}}$, which contained compost (CP)

\begin{tabular}{|c|c|c|c|c|c|c|c|c|}
\hline \multirow{2}{*}{ Media } & \multicolumn{3}{|c|}{ Porosity $\left(\mathrm{m}^{3} \mathrm{~m}^{-3}\right)$} & \multicolumn{2}{|c|}{$\mathrm{D} / \mathrm{D}_{0}^{2)}$} & \multirow{2}{*}{$\begin{array}{c}\mathrm{K}_{\mathrm{s}} \\
\left(\mathrm{m} \mathrm{s}^{-1}\right)\end{array}$} & \multirow{2}{*}{$\begin{array}{c}\mathrm{PAW}^{3)} \\
\left(\mathrm{m}^{3} \mathrm{~m}^{-3}\right)\end{array}$} & \multirow{2}{*}{$\begin{array}{c}\mathrm{Bd} \\
\left(\mathrm{Mg} \mathrm{m}^{-3}\right)\end{array}$} \\
\hline & Total & Macro & Capillary & $-6 \mathrm{kPa}$ & $-100 \mathrm{kPa}$ & & & \\
\hline WTR & $0.660^{\mathrm{a}}$ & $0.205^{\mathrm{b}}$ & $0.455^{\mathrm{a}}$ & $0.033^{\mathrm{b}}$ & $0.080^{\mathrm{b}}$ & $2.28 \times 10^{-3 \mathrm{a}}$ & $0.119^{c}$ & $0.77^{\mathrm{b}}$ \\
\hline DGS & $0.485^{\mathrm{b}}$ & $0.181^{\mathrm{b}}$ & $0.304^{c}$ & $0.012^{c}$ & $0.035^{c}$ & $1.10 \times 10^{-5 b}$ & $0.192^{\mathrm{a}}$ & $1.37^{\mathrm{a}}$ \\
\hline $\mathrm{WTR}_{\mathrm{CP}}{ }^{1)}$ & $0.677^{\mathrm{a}}$ & $0.313^{\mathrm{a}}$ & $0.364^{\mathrm{b}}$ & $0.050^{\mathrm{a}}$ & $0.111^{\mathrm{a}}$ & $3.68 \times 10^{-3 \mathrm{a}}$ & $0.107^{c}$ & $0.74^{\mathrm{b}}$ \\
\hline $\mathrm{DGS}_{\mathrm{CP}}^{11}$ & $0.486^{\mathrm{b}}$ & $0.189^{b}$ & $0.297^{c}$ & $0.024^{\text {be }}$ & $0.080^{\mathrm{b}}$ & $6.85 \times 10^{-5 b}$ & $0.161^{b}$ & $1.36^{\mathrm{a}}$ \\
\hline
\end{tabular}

1) The compost was added to WTR and DGS at the rate of $10 \%$ of the dry-mass.

${ }^{2)}$ Relative gas diffusivities $\left(\mathrm{D} / \mathrm{D}_{0}\right)$ at -6 and $-100 \mathrm{kPa}$ matric potentials.

3) Plant-available water (water retained between -6 and $-1,500 \mathrm{kPa}$ )

Different superscript letters (a-c) indicate significant difference between the treatments at $p<0.05$ according to the Tukey's test with 3 replications.

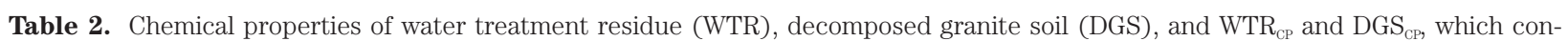
tained compost (CP)

\begin{tabular}{|c|c|c|c|c|c|c|c|c|c|c|c|}
\hline \multirow{3}{*}{ Media } & \multirow{3}{*}{$\begin{array}{c}\mathrm{pH} \\
\left(\mathrm{H}_{2} \mathrm{O}\right)\end{array}$} & \multirow{2}{*}{$\mathrm{EC}$} & Total & Total & \multirow{3}{*}{$\mathrm{C} / \mathrm{N}$} & \multirow{2}{*}{$\begin{array}{c}\text { Avail. } \\
\mathrm{P}_{2} \mathrm{O}_{5}\end{array}$} & \multirow{2}{*}{$\begin{array}{c}\mathrm{P}_{2} \mathrm{O}_{5} \text { ad. } \\
\text { Coef. }\end{array}$} & \multirow{2}{*}{ CEC } & \multicolumn{3}{|c|}{ Exchangeable bases } \\
\hline & & & $\mathrm{C}$ & $\mathrm{N}$ & & & & & $\mathrm{K}$ & $\mathrm{Ca}$ & $\mathrm{Mg}$ \\
\hline & & $\mathrm{dS} \mathrm{m} \mathrm{m}^{-1}$ & \multicolumn{2}{|c|}{$\mathrm{g} \mathrm{kg}^{-1}$} & & \multicolumn{2}{|c|}{$\mathrm{mg} \mathrm{kg}^{-1}$} & \multicolumn{4}{|c|}{$\operatorname{cmol}(+) \mathrm{kg}^{-1}$} \\
\hline WTR & 6.4 & 0.4 & 64.8 & 4.5 & 14.4 & 2.4 & 26702.3 & 17.2 & 0.7 & 8.3 & 0.2 \\
\hline DGS & 7.1 & 0.3 & 0.5 & 0.1 & 5.0 & 6.4 & 1878.9 & 8.9 & 0.2 & 11.3 & 7.6 \\
\hline $\mathrm{WTR}_{\mathrm{CP}}^{11}$ & 6.3 & 1.3 & 82.5 & 5.9 & 14.0 & 7.3 & 26530.0 & 17.9 & 13.5 & 9.5 & 1.2 \\
\hline $\mathrm{DGS}_{\mathrm{CP}}^{11)}$ & 7.0 & 0.7 & 12.2 & 1.0 & 12.2 & 6.9 & 24380.0 & 9.6 & 11.4 & 12.3 & 8.4 \\
\hline
\end{tabular}

1) The compost was added to WTR and DGS at the rate of $10 \%$ of the dry-mass.

EC: electric conductivity; CEC: cation exchange capacity; Avail. $\mathrm{P}_{2} \mathrm{O}_{5}$ : plant-available phosphorus; $\mathrm{P}_{2} \mathrm{O}_{5}$ ad. Coef.: phosphate adsorption coefficient. 


\section{Growths of the red pepper}

The red pepper growth in $\mathrm{WTR}_{\mathrm{CP}}$ and $\mathrm{DGS}_{\mathrm{CP}}$ (averaged for the 6 replications) are shown in Fig. 1. The growth of the root-collar diameter and dry mass of the red pepper, was significantly higher in $\mathrm{WTR}_{\mathrm{CP}}$ than in $\mathrm{DGS}_{\mathrm{CP}}$. However, the height growth was not significantly different between the $\mathrm{WTR}_{\mathrm{CP}}$ and $\mathrm{DGS}_{\mathrm{CP}}$.
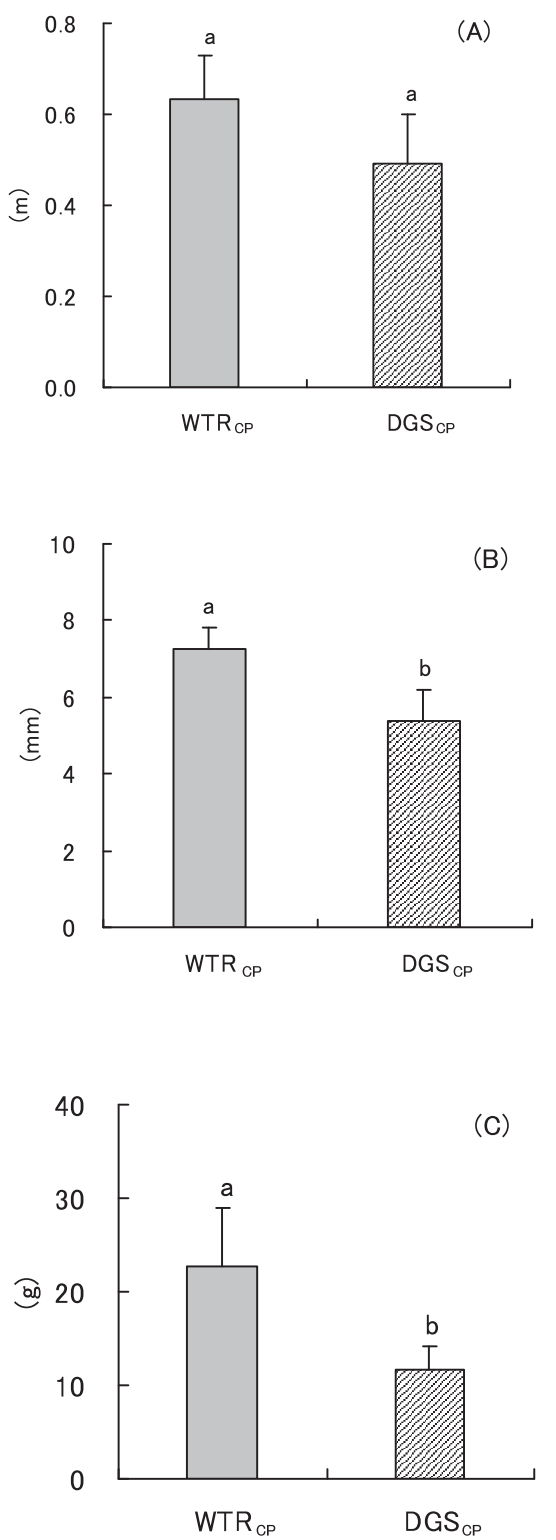

Fig. 1. Growth of the red pepper in the water treatment residue $\left(\mathrm{WTR}_{\mathrm{CP}}\right)$ and decomposed granite soil $\left(\mathrm{DGS}_{\mathrm{CP}}\right)$, which contained compost (CP), at the end of experiment. (A) Height growth, (B) Root-collar diameter, (C) Dry mass. Different alphabets above the columns indicate a significant difference between the treatments at $p<0.05$, according to the t-test. The error bars indicate the standard deviations (for 6 replications)

\section{DISCUSSION}

\section{Difference in the physical properties between WTR $_{\mathrm{CP}}$ and DGS $\mathrm{CP}_{\mathrm{C}}$}

When oxygen was not provided adequately to soil, respiration of plant roots was obstructed (Janick, 1986). According to Glinski and Stepniewski (1985), D/D of greater than 0.02 is required for plant roots to the normal respiration. The $\mathrm{D} / \mathrm{D}_{0}$ of the $\mathrm{WTR}_{\mathrm{CP}}$ was higher than that of $\mathrm{DGS}_{\mathrm{CP}}$, but the $\mathrm{D} / \mathrm{D}_{0}$ of both $\mathrm{WTR}_{\mathrm{CP}}$ and $\mathrm{DGS}_{\mathrm{CP}}$ was over 0.02 , thus aerobic respiration of plant roots can be done normally. The PAW of the $\mathrm{WTR}_{\mathrm{CP}}$ was lower than that of the DGS $_{\mathrm{CP}}$ (Table 2). Generally the amount of available water, which is different between growth mediums, is one of the growth limiting factors. However, there would be little influence of the PAW on the seedling growth of the red pepper in our study, because the seedings were watered as needed. Since the coagulants like aluminum, iron salts and/or organic polymers, added during the water treatment process, bind the silt and clay, the aggregates of WTR are highly stable and have a limited potential of swelling during water absorption (Moodley and Hughes, 2006). Therefore, the $\mathrm{K}_{\mathrm{s}}$ of the $\mathrm{WTR}_{\mathrm{CP}}$ was higher than that of the $\mathrm{DGS}_{\mathrm{CP}}$ (Fig. 2).

It is known that permeability and aeration of the DGS were poor because DGS, composed of sands and clays, was easy to be compacted by receiving pressures (Masuda, 1992). Therefore, the $\mathrm{D} / \mathrm{D}_{0}$ and $\mathrm{K}_{\mathrm{s}}$ of the $\mathrm{DGS}_{\mathrm{CP}}$ were lower than those of $\mathrm{WTR}_{\mathrm{CP}}$, and the porosity of the DGS $_{\mathrm{CP}}$ was lower than that of the $\mathrm{WTR}_{\mathrm{CP}}$.

Addition of the CP to the WTR did not change the PAW, $K_{s}$ and $\mathrm{Bd}$ (Table 1). Since the $\mathrm{D} / \mathrm{D}_{0}$ and $\mathrm{K}_{\mathrm{s}}$ of the WTR were already high enough, the improvement of these physical properties was not promising. The results suggest that addition of the $\mathrm{CP}$ has a negative effect on the PAW. Since the CP used here was too coarse, the macro porosity of the WTR might have increased largely, causing the decrease in water retention ability. In order to improve the PAW, finer and humified OM like sphagnum peat moss is better to be added. Additionally, measurement of the physical properties will be necessary after the start of plant growing in CP added WTR because plant growth will be accelerated by the decomposition of $\mathrm{CP}$, which will changes in the physical properties of WTR.

\section{Difference in the chemical properties between $\mathbf{W T R}_{\mathrm{CP}}$ and $\mathbf{D G S} \mathbf{S}_{\mathrm{CP}}$}

The $\mathrm{pH}$ of the $\mathrm{WTR}_{\mathrm{CP}}$ and $\mathrm{DGS}_{\mathrm{CP}}$ were 6.3 and 7.0, which were within the adequate range of 6 to 7 for plant growth (Janick, 1986). The EC of the $\mathrm{WTR}_{\mathrm{CP}}$ and $\mathrm{DGS}_{\mathrm{CP}}$ were 1.3 and $0.7 \mathrm{dS} \mathrm{m}^{-1}$ (Table 2). EC of below $4 \mathrm{dS}$ $\mathrm{m}^{-1}$ was associated with reduced plant growth caused by soil salinity. Elliott and Dempsey (1991) reported that the total-N of the WTR ranged from 4.4 to $10 \mathrm{~g}$ $\mathrm{kg}^{-1}$. Dayton and Basta (2001) reported that the CEC of the WTR ranged from 13.6 to $56.5 \mathrm{cmol} \mathrm{kg}^{-1}$, which was considerably greater than that of the typical soil of less than 3.5 to $35.6 \mathrm{cmol} \mathrm{kg}^{-1}$. The total-N and CEC were higher in $\mathrm{WTR}_{\mathrm{CP}}$ than in $\mathrm{DGS}_{\mathrm{CP}}$ in our study. The high 
CEC and total-N were associated with the $\mathrm{WTR}_{\mathrm{CP}}$, indicating that a growth medium had an ability to supply nutrients for the red pepper growth.

On the other hand, the plant-available $\mathrm{P}$ of the $\mathrm{WTR}_{\mathrm{CP}}$ was $7.3 \mathrm{mg} \mathrm{kg}{ }^{-1}$ in our study, which was slightly lower than that of the adequate soil of $12 \mathrm{mg} \mathrm{kg}^{-1}$ for most crops (Tisdale et al., 1985). However, the P-adsorption coefficient, which was associated with $\mathrm{P}$-adsorption capability, was higher for WTR than for DGS. Elliott and Dempsey (1991) reported that the P content of the WTR was typically low. It is known that the P-adsorption capability of the WTR can make soil P unavailable to plants (e.g., Elliott and Singer, 1988; Dayton and Basta, 2001). The chemical properties of the $\mathrm{WTR}_{\mathrm{CP}}$ were adequate for plant growth. None of the $\mathrm{WTR}_{\mathrm{CP}}$ was considered unsuitable as alternative material of the DGS $_{\mathrm{CP}}$ in terms of the supply of nutrients, excepting the $\mathrm{P}$ content.

\section{Difference in the red pepper growth between the WTR $_{\mathrm{CP}}$ and $\mathrm{DGS} \mathrm{S}_{\mathrm{CP}}$ and its cause}

The root-collar diameter and dry mass of the red pepper were significantly higher in $\mathrm{WTR}_{\mathrm{CP}}$ than in $\mathrm{DGS}_{\mathrm{CP}}$ (Fig. 3). Rengasamy et al. (1980) and Kim et al.(2002) reported that the plant growth was promoted by the addition of WTR due to the relatively high total-N, CEC and $\mathrm{Ca}^{2+}$ of the WTR, improved bulk density, hydraulic conductivity, and water-holding capacity. Park et al. (2010) reported that the WTR had a good possibility to be used as a planting base material instead of the DGS from the view point of aeration, water retention, and permeability. Because the growth media of the WTR could provide beneficial plant nutrition and better physical properties, the growths of the red pepper were better in $\mathrm{WTR}_{\mathrm{CP}}$ than in $\mathrm{DGS}_{\mathrm{CP}}$.

On the other hand, plant-available P and crop yield were significantly lower at higher application rates of WTR (e.g., Elliott and Singer, 1988; Dayton and Basta, 2001). Typically, soil P availability was significantly reduced at WTR application rates above 10\% (Dayton and Basta, 2001). However, Ippolito et al. (1999) reported that alternative soil material to which fertilizer and/or OM such as compost and biosolids were added, mitigate soil $\mathrm{P}$ deficiencies. In our study, the $\mathrm{WTR}_{\mathrm{CP}}$ produced larger growth of the red pepper without creating a purple venation of leaves indicated by Elliott and Singer (1988) and growth disorder according to deficiency of $\mathrm{P}$ was not observed, because addition of the CP to the WTR might corrected P deficiencies during the red pepper growth. Therefore, the growths of the red pepper were better in $\mathrm{WTR}_{\mathrm{CP}}$ than in DGS $_{\mathrm{CP}}$.

\section{CONCLUSIONS}

The chemical properties of total-N and CEC, and the physical properties of $\mathrm{D} / \mathrm{D}_{0}$ and $\mathrm{K}_{\mathrm{s}}$ were better for $\mathrm{WTR}_{\mathrm{CP}}$ than for DGS $\mathrm{CP}_{\mathrm{CP}}$. The growth of the red pepper was better for $\mathrm{WTR}_{\mathrm{CP}}$ than for $\mathrm{DGS}_{\mathrm{CP}}$ because the properties of the $\mathrm{WTR}_{\mathrm{CP}}$ were beneficial to the growth.
However, the improvement of these physical properties of WTR by the addition of the CP was not promising, because $\mathrm{D} / \mathrm{D}_{0}$ and $\mathrm{Ks}$ were already high enough in WTR. The macro porosity of the WTR might increase largely by the addition of the $\mathrm{CP}$, because the CP used was too coarse, which caused the decrease in water retention ability.

It is necessary to add fertilizer and/or OM for mitigate soil P deficiencies, when a WTR is reused actually as a growth medium. The chemical and physical properties of the $\mathrm{WTR}_{\mathrm{CP}}$ were adequate for red pepper growth. $\mathrm{WTR}_{\mathrm{CP}}$ has a possibility to be used as an alternative material of DGS.

\section{ACKNOWLEDGEMENTS}

The authors express their grateful thanks to Beppu Shoufuen Co., Ltd. and Fujiki Co., Ltd. for their financial supports of this research. The authors also express the thanks to Dr. T. Fukuda, Irrigation Engineering Lab., Kyushu University, for his technical support for the laboratory analyses.

\section{REFERENCES}

AICAF 1993 Handbook of tropical vegetable cultivation. Association for International Cooperation of Agriculture and Forestry, Tokyo, Japan, pp. 25-26

Ahmed, M., C. D. Grant, J. M. Oades and P. Tarrant 1997 Water treatment sludge: potential for use as a soil ameliorant. Urban Water Res. Assoc. of Australia, Research report No. 106 , p. 51

Babatunde, A. O. and Y. Q. Zhao 2007 Constructive approaches toward water treatment works sludge management: An international review of beneficial reuses. Critical Reviews in Environmental Science and Technology, 37: 129-164

Bigelow, C. A., D. C. Bowman and D. K. Casseld 2004 Physical properties of three sand size classes amended with inorganic materials or sphagnum peat moss for putting green rootzones. Crop. Sci., 44: 900-907

Dane, J. H. and J. W. Hopmans 2002a Hanging water column. In "Methods of soil analysis. Part 4: Physical methods", ed. by J. H. Dane and G. C. Topp, SSSA Book Ser. No. 5. SSSA, Madison, Wisconsin (USA), pp. 680-688

Dane, J. H. and J. W. Hopmans 2002b Pressure plate extractor. In "Methods of soil analysis. Part 4: Physical methods", ed. by J. H. Dane and G. C. Topp, SSSA Book Ser. No. 5. SSSA, Madison, Wisconsin (USA), pp. 688-690

Dayton, E. A. and N. T. Basta 2001 Characterization of drinking water treatment residuals for use as a soil substitute, Water Environ. Res., 73: 52-57

Elliott, H. A., B .A. Dempsey and P. J. Maille 1990 Contents and fractionation of heavy metals in water treatment sludges. $J$. Environ. Qual., 19: 330-334

Elliott, H. A. and L. M. Singer 1988 Effect of water treatment sludge on growth and elemental composition of tomato (Lycopersicon esculentum) shoots. Commun. Soil Sci. Plant Anal., 19: 345-354

Flint, L. E. and A. L. Flint 2002 Particle density, Porosity. In "Methods of soil analysis. Part 4: Physical methods", ed. by J. H. Dane and G. C. Topp, SSSA Book Ser. No. 5. SSSA, Madison, Wisconsin (USA), pp. 229-254

Furukawa, Y., D. Aizu and T. Fujita 2006 A study on the application of clean-water sludge as a geomaterial. J. Japan Soc. Civil Engin., 813: 203-214 (in Japanese with English summary)

Gee, G. W. and D. Or 2002 Particle-size analysis. In "Methods 
of soil analysis. Part 4: Physical methods", ed. by J. H. Dane and G. C. Topp, SSSA Book Ser. No. 5. SSSA, Madison, Wisconsin (USA), pp. 255-293

Glinski, J. and W. Stepniewski 1985 Soil aeration and its role for plants. CRC Press, Boca Raton.

Heil, D. M. and K. A. Barbarick 1989 Water treatment sludge influence on the growth of sorghum-sudangrass. $J$. Environ. Qual., 18: 292-298

Hyde, J. E. and T. F. Morris 2004 Phosphorus availability from phosphorus-ammended water treatment residual. Commun. Soil Sci. Plant Anal., 35: 1033-1046

Ippolito, J. A., K. A. Barbarick and E. F. Redente 1999 Co-application effects of water treatment residuals and biosolids on two range grasses. J. Environ. Qual., 28: 16441650

Janick, J. 1986 Horticultural science. 4th ed. W. H. Freeman and Co., New York. pp. 195-308

Kim, J. G., S. S. Lee, H. S. Moon and I. M. Kang 2002 Land application of alum sludge from water purification plant to acid mineral soil treated with acidic water. Soil Sci. Plant Nutr., 48: $15-22$

Kuo, S. 1996 Phosphorus. In "Methods of Soil Analysis. Part 3: Chemical methods", ed. D. L. Spark, A. L. Page, P. A. Helmke, R. H. Loepppert, P. N. Soltanpour, M. A. Tabatabai, C. T. Johnston and M. E. Sumner, SSSA, Madison, Wisconsin (USA), pp. 869-919

Masuda, T. 1992 Studies on the characteristics of Masa soil as a medium for tree growth and methods for its improvement. Journal of the Japanese Institute of Landscape Architects, 56: 138-145 (in Japanese)

Moodley, M. and J. C. Hughes 2006 The effects of a polyacrylamide-derived water treatment residue on the hydraulic conductivity, water retention and evaporation of four contrasting South African soils and implications for land disposal. Water Sci Technol., 54: 227-234

Moodley, M., M. A. Johnston, J. C. Hughes and L. W. Titshall 2004 Effects of a water treatment residue, lime, gypsum and polyacrylamide on the water retention and hydraulic conductivity of two contrasting soils under field conditions in KwaZulu-Natal, South Africa. Aust. J. Soil Res., 42: 273282

Osozawa, S. 1987 Measurement of soil-gas diffusion coefficient for soil diagnosis. Soil Phys. Condit. Plant Growth., 55: 53-60 (in Japanese with English summary)

Pan, J. R., C. Huang and S. Lin 2004 Reuse of fresh water sludge in cement making. Water Sci. Technol., 50: 183-188
Park, S. G., H. Yahata, K. Saeki, K. Kurosawa and Y. J. Kim 2009 Physical properties of water treatment residue and their effects on plant growth as a substitute soil. J. Fac. Agr., Kyushu Univ., 54: 481-487

Park, S. G., M. Ohashi, K. Kurosawa, Y. J. Kim and H. Yahata 2010 Evaluation of water treatment residue as a soil substitute material compared to decomposed granite soil in terms of physical properties (in press)

Ramadan, M. O., H. A. Fouad and A. M. Hassanain 2008 Reuse of water treatment plant sludge in brick manufacturing. $J$. Appl. Sci. Res., 4: 1223-1229

Reatto, A., da Silva E. Medrado, A. Bruand, Martins E. Souza and J. E. F. W. Lima 2008 Validity of the centrifuge method for determining the water retention properties of tropical soils. Soil Sci. Soc. Am. J., 72: 1547-1553

Rengasamy, P., J. M. Oades and T. W. Hancock 1980 Improvement of soil structure and plant growth by addition of alum sludge. Commun. Soil Sci. Plant Anal., 11: 533-545

Reynolds, W. D., D. E. Elrick, E. G. Youngs, A. Amoozegar, H. W. G. Booltink and J. Bouma 2002 Saturated and field-saturated water flow parnmeters. In "Methods of soil analysis. Part 4: Physical methods", ed. by J. H. Dane and G. C. Topp, SSSA Book Ser. No. 5. SSSA, Madison, Wisconsin (USA), pp. 797-878

Rolston, D. E. and P. Moldrup 2002 Gas Diffusivity In "Methods of Soil Analysis. Part 4: Physical methods", ed. by J. H. Dane and G. C. Topp, SSSA Book Ser. No. 5. SSSA, Madison, Wisconsin (USA), pp. 1113-1139

Roppongi, K. 1993 Application for horticultural nursery soil of sludges produced from water purification of mixing with hull and animal compost. Jpn. J. Soil Sci. Plant Nutr., 64 385-392 (in Japanese with English summary)

SEAC 1997 Soil and environmental analysis. Haku-sya. Tokyo, pp. 195-384 (in Japanese)

Sumner, M. E. and W. P. Miller 1996 Cation exchange capacity and exchange coefficients. In "Methods of Soil Analysis. Part 3: Chemical methods", ed. D. L. Spark, A. L. Page, P. A. Helmke, R. H. Loepppert, P. N. Soltanpour, M. A. Tabatabai, C. T. Johnston and M. E. Sumner, SSSA, Madison, Wisconsin (USA), pp. 1201-1229

Tisdale, S. L., W. L. Nelson and J. D. Beaton 1985 Soil Fertility and Fetilizers. 4th Ed. Macmillan, New York, pp. 754

Titshall, L. W. and J. C. Hughes 2005 Characterization of some South African water treatment residues and implications for land application. Water SA., 31: 299-307 